\title{
Associations among Chronic Obstructive Pulmonary Disease and Sleep-Disordered Breathing in an Urban Male Working Population in Japan
}

\author{
Masanori Azuma ${ }^{a}$ Kazuo Chin ${ }^{b}$ Chikara Yoshimurab Misa Takegamid, h \\ Ken-ichi Takahashi ${ }^{i}$ Kensuke Sumi $^{\text {f }}$ Takaya Nakamurag $^{9}$ \\ Yukiyo Nakayama-Ashidac Itsunari Minamic Sachiko Horitak Yasunori Okal \\ Toru Oga $^{b}$ Tomoko Wakamura ${ }^{\mathrm{e}}$ Shun-ichi Fukuharad Michiaki Mishima ${ }^{\mathrm{a}}$ \\ Hiroshi Kadotani ${ }^{j}$

\begin{abstract}
Departments of a Respiratory Medicine and ${ }^{\mathrm{b}}$ Respiratory Care and Sleep Control Medicine, and ${ }^{\mathrm{c} H o r i z o n t a l}$ Medical Research Organization, Graduate School of Medicine, dDepartment of Epidemiology and Healthcare Research, Graduate School of Medicine and Public Health, and e Environmental Health Nursing, Graduate School of Medicine, Human Health Sciences, Kyoto University, ${ }^{\mathrm{f}}$ Department of Respiratory Medicine, National Hospital Organization Minami Kyoto Hospital, and ${ }^{9}$ Department of Respiratory Medicine, Kyoto City Hospital, Kyoto, hepartment of Prevalence Medicine and Epidemiologic Informatics, Research and Development Initiative Center, National Cerebral and Cardiovascular Center, Osaka, 'Department of Respiratory Medicine, Otsu Red Cross Hospital, and jDepartment of Psychiatry, Shiga University of Medical Science, Otsu, ${ }^{k}$ Department of Human Nursing, Faculty of Human Health, Sonoda Women's University, Amagasaki, and 'Department of Sleep Control Medicine, Graduate
\end{abstract} \\ School of Medicine, Ehime University, Matsuyama, Japan
}

\section{Key Words}

Chronic obstructive pulmonary disease - Sleep apnea ·

Overlap syndrome · Actigraph · Portable monitoring

\begin{abstract}
Background: There are few reports about sleep disturbances in patients with chronic obstructive pulmonary disease (COPD) in Asian countries. Objectives: To investigate the associations between sleep-disordered breathing (SDB) with hypoxemia and sleep quality, including sleep duration, in patients with COPD, we measured SDB and sleep quality including the objective sleep duration determined by an acti-
\end{abstract}

\section{KARGER} www.karger.com/res
E-Mail karger@karger.com graph and portable monitoring. Methods: A cross-sectional epidemiological health survey of 303 male employees (means \pm SD: age $43.9 \pm 8.2$ years; BMl $24.0 \pm 3.1$ ) was conducted. Sleep quality was measured using the Epworth Sleepiness Scale (ESS) and the Pittsburgh Sleep Quality Index (PSQI). A respiratory disturbance index (RDI) $\geq 5$ indicated SDB. Results: Nineteen subjects (6.3\%) had COPD. Among these, 11 (3.6\%) had COPD with SDB (overlap syndrome). Sleep duration, ESS, and PSQI scores were not significantly different between COPD patients and normal control subjects. However, COPD patients had significantly longer sleep latency $(p=0.019)$, a lower sleep efficiency $(p=0.017)$, and a higher sleep fragmentation index $(p=0.041)$ and average (c) 2014 S. Karger AG Basel

$0025-7931 / 14 / 0883-0234 \$ 39.50 / 0$ 
activity ( $p=0.0097$ ) during sleep than control subjects. They also had a significantly higher RDI and more severe desaturation during sleep than control subjects $(p<0.01)$. The differences remained after adjustment for age and BMI but disappeared following adjustment for RDI. Conclusions: COPD patients with even mild-to-moderate airflow limitations had nocturnal desaturation and RDI-related impaired sleep quality without significant symptoms.

(c) 2014 S. Karger AG, Basel

\section{Introduction}

Chronic obstructive pulmonary disease (COPD) is a common condition caused mainly by smoking, and it has become a burden worldwide [1]. The prevalence of COPD in Japan is $8.6 \%$, which is comparable to that in other countries [2]. The literature reporting on sleep quality in patients with COPD dates back to 1985 when Flenley [3] coined the term 'overlap syndrome' to apply to patients with both COPD and obstructive sleep apnea and to 1987 when Klink and Quan [4] examined sleep quality in 2,187 subjects. Since then, multiple reports have confirmed the presence of increasing sleep complaints with increasing severity of COPD [5]. In the Sleep Health Heart Study (SHHS), co-occurrence of COPD and obstructive sleep apnea in the same individual appeared to have implications for sleep quality and nocturnal oxygenation [6]. In addition, a recent report showed that patients with overlap syndrome had a higher risk of exacerbation and higher mortality than COPD-only patients [7]. However, additional data may prove clinically useful because nighttime symptoms and sleep disturbances in COPD are generally not considered in the clinical management of patients with COPD [8]. The prevalence of overlap syndrome was shown to be $3-4 \%$ for males in the USA and Europe $[9,10]$. Recently, Shiina et al. [11] showed the possibility of cardiovascular sequelae in patients with overlap syndrome in Japan. However, there has been no population-based study of overlap syndrome in Asian regions.

In the SHHS, sleep in COPD patients was investigated mainly by polysomnography (PSG) at home and the measurement of daytime somnolence using the Epworth Sleepiness Scale (ESS) [6]. In the majority of other studies, objective sleep assessment in COPD patients was evaluated by laboratory-based PSG [12]. Although PSG is the gold standard method for sleep studies, it is expensive and it is a complex procedure performed by trained technologists. Actigraphy is much less expensive and al-

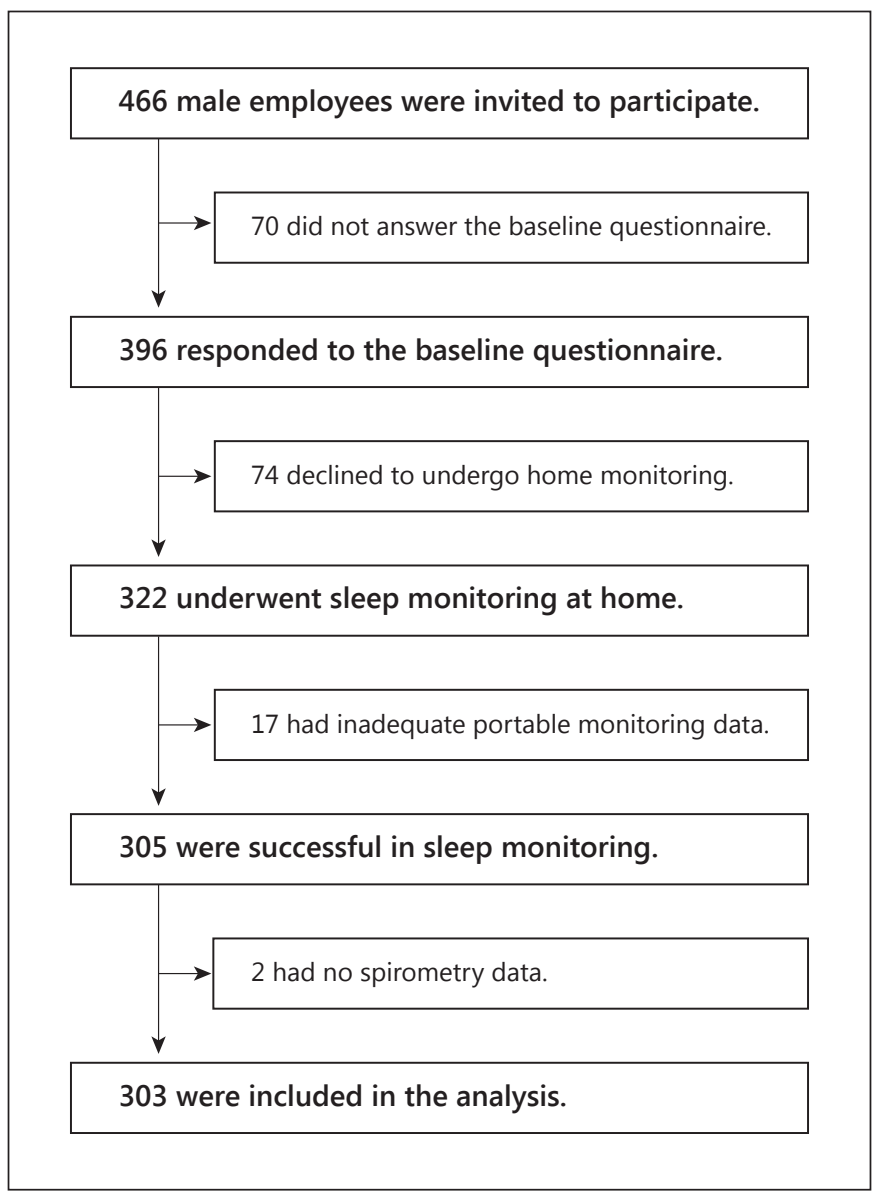

Fig. 1. Flowchart of the study subjects.

lows prolonged objective monitoring of the sleep-wake cycle. An actigraph is a small wrist-worn device that contains an accelerometer to monitor physical activity. According to the physical activity, the sleep/wake state is identified, and sleep parameters such as sleep duration and sleep efficiency are calculated. Although the actigraph may be a useful device for sleep assessment in the home environment, only one report has shown objectively determined sleep disturbances in patients with COPD using actigraphy [12]. That study did not investigate sleep-disordered breathing (SDB), which has a significant effect on sleep disturbance and mortality in COPD patients.

We hypothesized that SDB with hypoxemia in patients with COPD has a significant association with sleep quality, including sleep duration. To test this hypothesis, we measured SDB using a portable monitor and sleep quality, including the objective sleep duration, using an actigraph. 


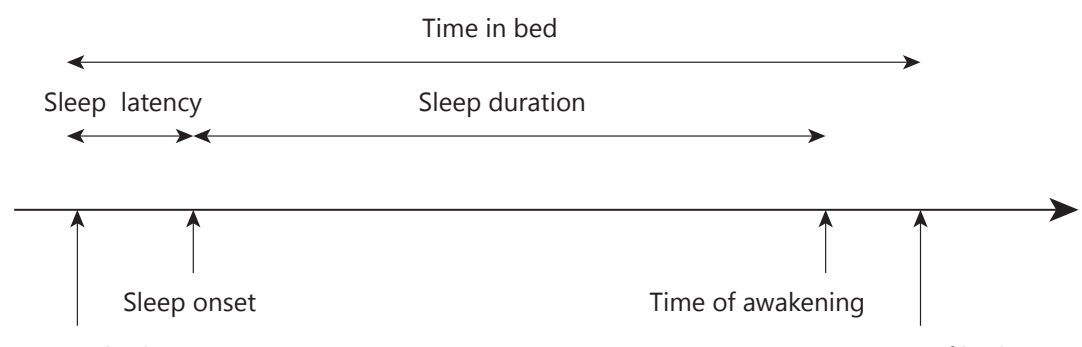

Went to bed

Got out of bed

Fig. 2. Definition of sleep parameters by actigraph.

\section{Methods}

\section{Subjects}

In Japan, almost $70 \%$ of people live in urban areas and $80 \%$ of workers are office workers. Among office workers, the prevalence of wholesale workers is highest (16.9\%) [13]. The study subjects were male employees of an urban wholesale company in Japan and were invited to participate in this study between January 2004 and December 2005. As there were few females in the company, only male employees were invited to participate. Of the 466 male subjects who were invited to participate, 396 answered the baseline questionnaire ( $85.0 \%$ of the invited participants). Of the questionnaire responders, 322 (69.1\%) underwent monitoring with an actigraph for 7 days and with a type 3 portable monitor for 2 nights at home. There were no significant differences in characteristics [such as age, BMI, number of current smokers, habitual snorers, drinkers, hypertensive individuals, ESS scores, total sleep time and sleep latency obtained from the Pittsburgh Sleep Quality Index (PSQI), and sleeping pill use] between subjects who underwent monitoring with home-based portable monitors and subjects who did not [14]. Data without oxygen saturation signals or indecipherable recordings were excluded from analysis. Data recorded for $<2 \mathrm{~h}$ were also excluded from analysis because such data were insufficient for analysis. When portable monitor data were available for both nights, we adopted the data from the second night [14]. Out of 644 portable monitor recordings, 63 could not be analyzed. One subject refused to perform the second recording. Data from 26 recordings were lost, probably due to technical or mechanical problems. No oxygen saturation data were available for 14 recordings. Five recordings were shorter than $2 \mathrm{~h}$. As a result, 17 subjects had inadequate portable monitoring data and 305 subjects (94.7\%) were analyzed for the prevalence of SDB [14]. Data from only 1 night were analyzed in 29 subjects and data from both nights were available for analyses in 276 subjects. In the present study, we reviewed those data in addition to results of spirometry. There were no spirometry data for 2 subjects. Finally, data on 303 subjects were analyzed (fig. 1). Written informed consent was obtained from all subjects. The study protocol was approved by the Kyoto University Graduate School and Faculty of Medicine Ethics Committee (IRB approval No. E-37).
Analysis of Data from the Actigraph and Portable Monitor

Each subject wore an actigraph (Actiwatch AW-Light; Mini Mitter, Bend, Oreg., USA) for 7 days and a type 3 portable monitor (Morpheus; Teijin, Tokyo, Japan, which is the same as Somté; Compumedics, Abbotsford, Vic., Australia) for 2 nights at home. We assessed the objective sleep quality and sleep pattern from data obtained by actigraphy. An actigraph is a small wristworn device that contains an accelerometer to monitor wrist movements per epoch. Scoring according to activity counts is used to identify the sleep/wake state and to determine sleep parameters such as the total sleep time, sleep latency, and sleep efficiency [15], which were validated by simultaneous measurement with an actigraph and PSG $[15,16]$. The average value calculated from actigraphy data for 7 days was used. To assess night-to-night sleep variability, the coefficient of variation $[\mathrm{CV}=(\mathrm{SD} / \mathrm{mean}) \times 100]$ for each parameter was calculated. Definitions of sleep parameters are shown in figure 2 . The time at which the participant went to bed and the time at which he arose were obtained from a diary. In this study, we used actigraphy to determine the beginning and the end of the sleep state. Sleep onset was estimated by noting sustained cessation of wrist movements on the actigraph tracing. The time of awakening was noted by the appearance of wrist movements on the actigraph tracing. Sleep durations were estimated by the length of time between sleep onset and final awakening. Sleep latency was defined by the time to sleep onset after going to bed. Sleep efficiency was defined as the percentage of total time spent asleep divided by the total time in bed. The sleep fragmentation index, an index of restlessness during sleep, was calculated via the summation of two percentages: (1) the percentage of the sleep period spent moving (an epoch with $>2$ activity counts is considered moving) and (2) the percentage of immobile phases (consecutive epochs with no movement) that are only $\leq 1 \mathrm{~min}$ long [17]. The average activity, which is a specific score from the actigraph indicating physical activity, was defined by the average per minute of activity counts during the sleep period [18]. These sleep parameters were analyzed with Actiware-Sleep version 3.4 (Mini Mitter).

Portable monitor records were visually inspected and scored. There were 4 respiratory doctors who specialize in analyzing and scoring sleep studies, and at least 2 of the 4 doctors scored the data (details were shown previously [14]). The respiratory disturbance index (RDI), which is the number of apneic and hypopneic epi- 
Table 1. Characteristics of the subjects

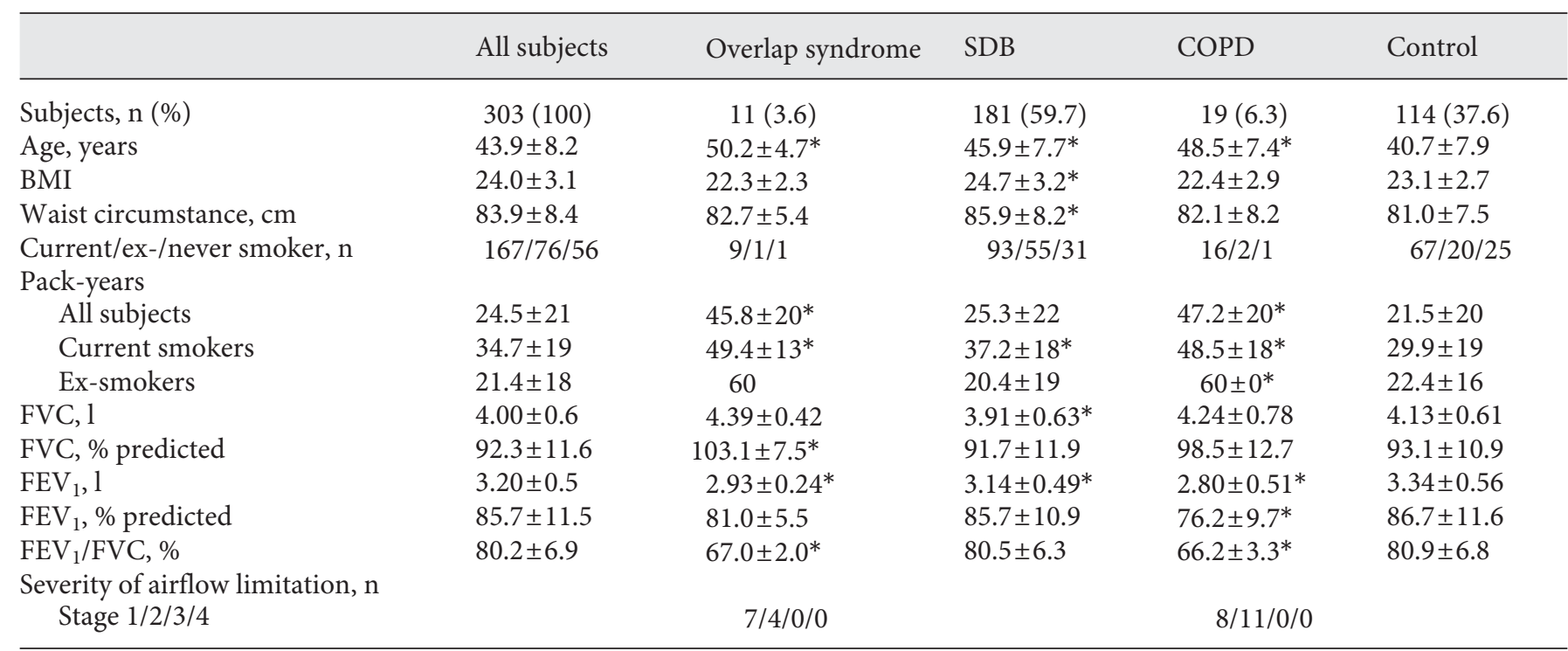

Values are presented as means \pm SD unless otherwise indicated. The analysis included 4 subjects with missing smoking information. $* \mathrm{p}<0.05$ vs. control subjects.

Table 2. Comparison of the prevalence of COPD, SDB, and overlap syndrome as defined by $\mathrm{FEV}_{1} / \mathrm{FVC}<70 \%$ or the $<5$ th percentile and RDI $\geq 5$ with or without ESS $>10$

\begin{tabular}{|c|c|c|c|}
\hline & \multirow{2}{*}{$\begin{array}{l}\text { Total, } \\
\text { n (\%) }\end{array}$} & \multicolumn{2}{|l|}{ COPD } \\
\hline & & $\begin{array}{l}\mathrm{FEV}_{1} / \mathrm{FVC} \\
<70 \% \\
19(6.2)\end{array}$ & $\begin{array}{l}\mathrm{FEV}_{1} / \mathrm{FVC} \\
<5 \text { th percentile } \\
40(13.2)\end{array}$ \\
\hline \multicolumn{4}{|l|}{ SDB, n (\%) } \\
\hline $\mathrm{RDI} \geq 5$ & $181(59.7)$ & $11(3.6)$ & $23(7.6)$ \\
\hline $\mathrm{RDI} \geq 5$ plus ESS $>10$ & $52(17.2)$ & $2(0.66)$ & $6(2.0)$ \\
\hline
\end{tabular}

sodes per hour of the analyzed time length based on the sleep duration, was calculated from data obtained from both the actigraph and the portable monitor for the same night as mentioned above [14]. Apnea (cessation of breathing for $\geq 10 \mathrm{~s}$ ) and hypopnea ( $>50 \%$ reduction in the amplitude of nasal pressure or respiratory effort associated with a more than $3 \%$ reduction in oxyhemoglobin saturation $\geq 10$ s) were scored blinded. Subjects with an RDI $\geq 5$ were considered to have SDB.

\section{Assessment of Subjective Sleep-Related Symptoms}

The modified Japanese version of the ESS was used to assess subjective sleepiness $[19,20]$ and the PSQI was used to assess subjective sleep quality and sleep disturbances over a 1-month time period $[21,22]$. Subjects also filled out a sleep diary during the survey period.

\section{Spirometry}

Spirometric testing to determine the forced vital capacity (FVC) and the forced expiratory volume in one second $\left(\mathrm{FEV}_{1}\right)$ was performed using a spirometer (Chestgraph HI-101; CHEST, Tokyo, Japan). Results were expressed as percentages of the predicted values, which were based on recommendations of the Japanese Respiratory Society (JRS) [23]. We used criteria for the diagnosis of COPD based on airflow limitation $\left(\mathrm{FEV}_{1} / \mathrm{FVC}<70 \%\right)$; however, a bronchial reversibility test could not be performed on our study subjects. Three subjects who had airflow limitation had a history of asthma and were excluded from the diagnosis of COPD. Classification of the severity of airflow limitations was as follows: stage 1: $\mathrm{FEV}_{1} / \mathrm{FVC}<70 \%, \mathrm{FEV}_{1} \geq 80 \%$ predicted; stage $2: \mathrm{FEV}_{1} / \mathrm{FVC}$ $<70 \%, 50 \% \leq \mathrm{FEV}_{1}<80 \%$ predicted; stage 3: $\mathrm{FEV}_{1} / \mathrm{FVC}<70 \%$, $30 \% \leq \mathrm{FEV}_{1}<50 \%$ predicted, and stage $4: \mathrm{FEV}_{1} / \mathrm{FVC}<70 \%, \mathrm{FEV}_{1}$ $<30 \%$ predicted.

In addition, we assessed the data using the $\mathrm{FEV}_{1} / \mathrm{FVC}<5$ th percentile (lower limit of normal; LLN) as the definition of COPD. The equations for the LLN of $\mathrm{FEV}_{1} / \mathrm{FVC}$ were based on recommendations of the JRS [23]. The LNN of FEV $\mathrm{FVV}_{1} / \mathrm{FV}$ for males was: $0.028 \times$ height $(\mathrm{cm})-0.19 \times$ age $+89.313-2 \times 6.147$. Five subjects who had a lower $\mathrm{FEV}_{1} / \mathrm{FVC}$ than the LLN of $\mathrm{FEV}_{1} / \mathrm{FVC}$ had a history of asthma and were excluded from the diagnosis of COPD using the LLN.

\section{Statistical Analysis}

It has been reported that the prevalence of sleep disturbances and COPD patients is approximately 33\% [24] and 9\% [2], respectively, among adults in the general population and that the rate of sleep disturbances among COPD patients is approximately $61 \%$ [8]. Based on these data, the sample size was set to achieve $80 \%$ power at a $5 \%$ significance level, and it was determined that there should be a sample size of 306 subjects in total. 
Table 3. Sleep assessment by type 3 monitor, ESS, and PSQI

\begin{tabular}{|c|c|c|c|c|c|}
\hline $\mathrm{RDI}, / \mathrm{h}$ & $10.6 \pm 11.4$ & $14.2 \pm 8.6^{* \dagger}$ & $16.1 \pm 11.9^{* \dagger}$ & $9.40 \pm 8.7^{* \dagger}$ & $2.44 \pm 1.4$ \\
\hline Mean $\mathrm{SpO}_{2}, \%$ & $95.9 \pm 1.8$ & $95.9 \pm 1.3^{*}$ & $95.4 \pm 1.7^{* \dagger}$ & $95.5 \pm 2.1^{* \dagger}$ & $96.7 \pm 1.6$ \\
\hline Lowest $\mathrm{SpO}_{2}, \%$ & $84.2 \pm 7.2$ & $80.6 \pm 11.2^{* \dagger}$ & $81.2 \pm 7.3^{* \dagger}$ & $82.4 \pm 9.6^{* \dagger}$ & $88.8 \pm 4.0$ \\
\hline \multicolumn{6}{|l|}{ PSQI component score } \\
\hline C1: sleep quality & $2.12 \pm 0.64$ & $2.18 \pm 0.75$ & $2.18 \pm 0.64^{*}$ & $2.02 \pm 0.67$ & $2.02 \pm 0.64$ \\
\hline C2: sleep latency & $0.32 \pm 0.54$ & $0.10 \pm 0.32$ & $0.29 \pm 0.52$ & $0.44 \pm 0.62$ & $0.35 \pm 0.57$ \\
\hline C3: sleep duration & $1.47 \pm 0.68$ & $1.73 \pm 0.47^{*}$ & $1.49 \pm 0.68$ & $1.53 \pm 0.51$ & $1.42 \pm 0.67$ \\
\hline C4: sleep efficiency & $0.072 \pm 0.33$ & $0.18 \pm 0.40$ & $0.072 \pm 0.33$ & $0.11 \pm 0.32$ & $0.071 \pm 0.32$ \\
\hline C5: sleep disturbance & $0.61 \pm 0.50$ & $0.70 \pm 0.48$ & $0.62 \pm 0.51$ & $0.72 \pm 0.46$ & $0.59 \pm 0.49$ \\
\hline ESS score & $8.19 \pm 4.3$ & $9.22 \pm 1.7$ & $8.28 \pm 4.4$ & $8.09 \pm 2.7$ & $8.04 \pm 4.1$ \\
\hline$>10^{\mathrm{a}}, \mathrm{n}(\%)$ & $80(26)$ & $2(18)$ & $52(29)$ & $3(16)$ & $28(25)$ \\
\hline
\end{tabular}

Values are presented as means \pm SD unless otherwise stated. ${ }^{*} \mathrm{p}<0.05$ vs. control subjects. ${ }^{\dagger} \mathrm{p}<0.05$ vs. control subjects after adjustment for age and BMI. ${ }^{\ddagger} \mathrm{p}<0.05$ vs. control subjects adjusted for RDI. a $\chi^{2}$ (SDB patients) and Fisher's exact (overlap syndrome and COPD patients) tests were used to compare prevalences with the control subject group.

Statistical analyses were performed using JMP version 9.0.0 statistical software (SAS Institute Inc., Cary, N.C., USA). p $<0.05$ was considered statistically significant. Results are expressed as means \pm SD. The statistical significance of differences between COPD (or overlap syndrome) patients and others was determined via nonparametric analysis using the Mann-Whitney U test because of the small number of COPD and overlap syndrome patients. The statistical significance of differences between SDB patients and control subjects was determined using an unpaired t test. We used analysis of covariance (ANCOVA) to adjust for age, BMI, and RDI. $\chi^{2}$ and Fisher's exact tests were used to calculate differences in categorized data.

\section{Results}

\section{Characteristics of the Subjects}

The characteristics of the 303 subjects are presented in table 1. Nineteen subjects (6.3\%) had COPD. Among these, 11 subjects $(3.6 \%)$ had COPD with SDB (overlap syndrome). Of the 303 subjects, 114 (37.6\%) had neither COPD nor SDB (control subjects). The severity of airflow limitation in the COPD patients was either stage 1 or stage 2. COPD patients defined by $\mathrm{FEV}_{1} / \mathrm{FVC}<\mathrm{LLN}$ instead of $\mathrm{FEV}_{1} / \mathrm{FVC}<70 \%$ included 40 subjects (13.2\%). Fifty-two subjects (17.2\%) had RDI $\geq 5$ and ESS $>10$ (table 2 ).

\section{Sleep Assessment in COPD Patients}

As shown in table 3 and figure 3, the COPD patients had worse sleep parameters than the control subjects. The COPD patients had significantly longer sleep latency $(\mathrm{p}=$ $0.019)$, a lower sleep efficiency $(p=0.017)$, a higher sleep fragmentation index $(\mathrm{p}=0.041)$, and a higher average activity $(\mathrm{p}=0.0097)$ than the control subjects. $\mathrm{FEV}_{1} \%$ predicted correlated significantly with sleep latency $(r=$ $-0.11 ; \mathrm{p}=0.0461)$, sleep efficiency $(\mathrm{r}=0.18 ; \mathrm{p}=0.0015)$, and average activity $(\mathrm{r}=-0.13 ; \mathrm{p}=0.0209)$. However, sleep duration, ESS, and component and global scores on the PSQI were not significantly different between COPD patients and control subjects. The prevalence of somnolent subjects (ESS >10) and poor sleepers (PSQI global score $\geq 6$ ) was not significantly different between COPD patients and control subjects $(p=0.56$ and $p=0.99$ by Fisher's exact test). The significant difference in RDI, mean $\mathrm{SpO}_{2}$, lowest $\mathrm{SpO}_{2}$, total sleep time with $\mathrm{SpO}_{2}$ $<90 \%$, sleep efficiency, sleep fragmentation index, and average activity remained after adjustment for age and BMI (table 3). However, after adjustment for RDI, the significant difference in mean $\mathrm{SpO}_{2}$, lowest $\mathrm{SpO}_{2}$, sleep efficiency, and sleep fragmentation index disappeared (table 3; fig. 3). There was no significant difference in the CV of 

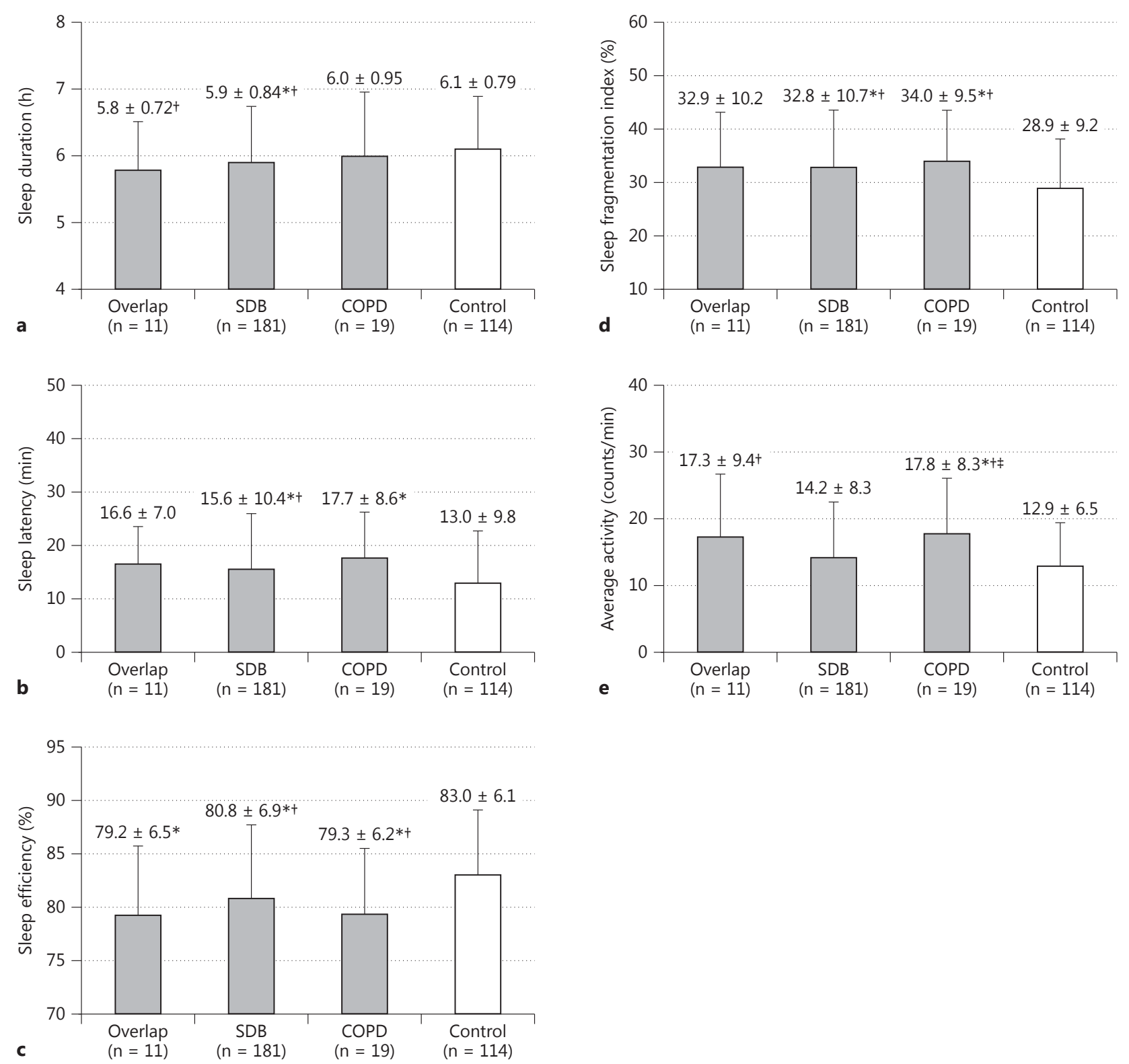

Fig. 3. Comparison of sleep assessment between COPD patients, SDB patients, and overlap syndrome patients and control subjects. ${ }^{*} \mathrm{p}<0.05$ vs. control subjects. ${ }^{\dagger} \mathrm{p}<0.05$ vs. control subjects after adjustment for age and BMI. ${ }^{\ddagger} \mathrm{p}<0.05$ vs. control subjects adjusted for RDI.

sleep parameters between COPD patients and control subjects after adjustment for age and BMI or for RDI.

\section{Assessment of Patients with Overlap Syndrome}

The overlap syndrome patients had worse sleep parameters than the control subjects. However, after adjust- ment for RDI, the significant differences disappeared (table 3; fig. 3). The FVC and $\mathrm{FEV}_{1} \%$ predicted of overlap syndrome patients were significantly higher than those of COPD-only patients $(4.39 \pm 0.42$ vs. $4.03 \pm 1.1$ liters, $\mathrm{p}=$ 0.035 , and $81.0 \pm 5.5$ vs. $69.6 \pm 10.7 \%, p=0.0093$, respectively). There were no significant differences between 
overlap syndrome and COPD-only patients in sleep parameters other than RDI $(14.2 \pm 8.6$ vs. $2.8 \pm 1.5 / \mathrm{h} ; \mathrm{p}=$ $0.0003)$. There were no significant differences between overlap syndrome and SDB-only patients in terms of sleep parameters. In the comparison with COPD only and SDB only, there were significant differences in terms of the average activity and RDI ( $18.5 \pm 7.1$ vs. $14.0 \pm 8.2$ counts $/ \mathrm{min}, \mathrm{p}=0.044$, and $2.81 \pm 1.5$ vs. $16.2 \pm 12.1 / \mathrm{h}$, $\mathrm{p}<0.0001$, respectively).

\section{Data Using the LLN of FEV $V_{1} / F V C$ for Sleep \\ Parameters}

The sleep parameters for COPD patients diagnosed with $\mathrm{LLN}$ of $\mathrm{FEV}_{1} / \mathrm{FVC}$ criteria were similar to those using fixed $\mathrm{FEV}_{1} / \mathrm{FVC}<70 \%$ criteria, except for sleep efficiency. The mean and CV of sleep efficiency $(79.5 \pm 5.4$ vs. $83.1 \pm 6.3 \%, \mathrm{p}=0.0011$, and $11.0 \pm 6.1$ vs. $7.81 \pm 4.5 \%$, $\mathrm{p}=0.0019$, respectively) in COPD patients with LLN criteria were significantly lower and higher, respectively, than those in control subjects. The significance remained after adjustment for age and BMI or for RDI.

\section{Discussion}

This is a cross-sectional study of an urban male working population in Japan that assessed the sleep quality and SDB of COPD patients and, to our knowledge, it is the first such study using actigraphy and portable monitoring in the home environment. The main findings are as follows: (1) COPD patients had impaired sleep quality and nocturnal oxygen saturation even with mild-to-moderate airflow limitations and few sleep-related symptoms; (2) the significant impairment of sleep quality in COPD patients disappeared after adjustment for RDI, and (3) the prevalence of overlap syndrome in urban middle-aged male employees in Japan was 3.6\% (11 of 303 subjects).

\section{Sleep Assessment in COPD Patients}

Patients with COPD commonly experience poor sleep efficiency, increased sleep latency, a decreased total sleep time, increased waking after sleep onset, and decreased stage N3 and stage R sleep [25]. These sleep disturbances may be related to multiple causes including demographic factors such as age and the presence of obesity, diseasespecific symptoms including wheezing and cough, and sleep disorders such as obstructive sleep apnea [8]. In our study, COPD patients had a lower sleep efficiency and higher sleep fragmentation than control subjects. This significance remained after adjustment for age and BMI but disappeared after adjustment for RDI. The SHHS is the largest population study evaluating sleep in COPD patients. Sleep and sleep-related symptoms were evaluated via PSG, ESS, SF-36, and a sleep habit questionnaire. In the SHHS, in the absence of SDB, there were no differences in ESS, sleep latency, or sleep efficiency between subjects with and without airflow limitations [6]. These results suggest that the poor sleep quality in COPD patients was largely related to SDB.

In the SHHS, objective assessment by PSG was performed, and subjective assessment by PSQI was not performed. In the present study, although the number of subjects was smaller than in the SHHS, we used both actigraphy and a sleep diary under usual circumstances for a week, and both the ESS and the PSQI. As our subjects were younger than those in the SHHS, who were in late middle age or elderly, we could evaluate younger (though middle-aged) patients with COPD, a condition that might cause several medical problems with increasing age and its progression.

It has been reported that nighttime symptoms, a forgotten dimension of COPD, are important in the management of COPD patients [8]. Previously, an association between objective measures of sleep quality derived from PSG and subjective complaints of difficulty initiating and maintaining sleep was described in patients with severe COPD [26]. However, several investigators have reported discrepancies between subjective data and surrogate markers of sleep and sleep disturbances [27]. In this study, it was confirmed that the objective sleep quality (sleep latency, efficiency, fragmentation, and average activity) was disturbed while the patients could not perceive such disturbances with the ESS or PSQI. Therefore, attention should be paid to sleep disturbances in COPD patients regardless of mild airflow limitations or the presence of few sleep-related symptoms.

In this study, we did not use a bronchodilator before spirometric testing. Moreover, we added data using the $\mathrm{FEV}_{1} / \mathrm{FVC}<5$ th percentile (LLN) criterion because it is one way to minimize potential misclassification [28]. The prevalence of COPD increased from 6.2 to $13.2 \%$ using LLN criteria. The sleep parameters by actigraphy were similar in COPD patients using the fixed criteria of $\mathrm{FEV}_{1}$ / FVC $<70 \%$ and in those with LLN criteria, except for the mean and CV of sleep efficiency, which was impaired independently of the RDI in those with the LLN criteria. However, the reason and pathological mechanism for the discrepancy between the two criteria are unknown. Studies following a bronchial reversibility test would provide further information. 
In this study, the mean ESS $(8.0 \pm 4.1)$ and PSQI (4.3 $\pm 2.1)$ scores were quite high even in the controls. Among these company employees, the mean sleep duration of the controls was only $6.1 \mathrm{~h}$, which is shorter than in the general population in Japan [29]. It has been reported that the mean commute time in this urban region is almost $90 \mathrm{~min}$ daily [30]. The short sleep duration in the controls might have induced these high ESS and PSQI scores.

\section{Overlap Syndrome in Japan}

In our population, which was predominantly males in their $40 \mathrm{~s}$, the prevalence of COPD was $6.3 \%$. In the Nippon COPD Epidemiology (NICE) study in Japan, which included males and females, the prevalence of COPD in persons in their 40s was 3.5\% [2]. The prevalence of COPD in males was about 3 times that in females (16.4 vs. $5.0 \%$ ) in the NICE study; therefore, using NICE study data, the prevalence of COPD in males in their 40 s could be estimated to be almost $5.3 \%$. Thus, our prevalence of COPD could be considered compatible with that shown in the NICE study. In our population, the prevalence of overlap syndrome, i.e. the coexistence of COPD and SDB, was 3.6\%. It has been reported that overlap syndrome occurs in 3\% of males in Europe [9]. A simple calculation based on the prevalence of COPD in the National Health and Nutrition Examination Survey study (16.8\%) and SDB in the Wisconsin Sleep Cohort Study (24\%) could estimate a prevalence of overlap syndrome of $4 \%$ in males $[10,31,32]$. Thus, our results are comparable to those of previous studies in the USA and Europe.

In this study, the prevalence of SDB (RDI $\geq 5$ ) was high. It was reported that the prevalence of SDB in 20072010 increased by more than $30 \%$ compared to 1988 1994 data [33]. In a relatively recent population-based study in a large metropolitan area of South America, the prevalence of SDB in males was $46.5 \%$, determined via lab-based full PSG [34]. In addition, in another recent report from Japan, the prevalence of RDI $\geq 15$ in males was more than $20 \%$, which was almost the same as the prevalence of RDI $\geq 15$ in our cohort $[14,35]$. Additionally, another possible reason is that we used a nasal pressure sensor to detect hypopnea. The American Academy of Sleep Medicine reported that a pressure sensor could detect hypopnea, especially slight hypopnea [36]. It was reported that a nasal pressure sensor could detect $25 \%$ more respiratory events than a thermistor [37]. In addition, in this study, the measurement was done under usual circumstances. More than half of the subjects in this study took alcohol before sleep and the mean sleep duration was short [14]. These factors might have induced the high prevalence of SDB (RDI $\geq 5)$.

In previous population-based studies, patients with overlap syndrome had a poorer quality of sleep and greater nocturnal oxygen desaturation than COPD-only patients $[5,8]$. In the present study, unlike in those studies, the degree of airflow limitation in overlap syndrome patients was significantly milder than in the COPD-only patients. This finding might be one of the reasons why we found no differences in sleep quality or nocturnal oxygen saturation between overlap syndrome and COPD-only patients. Considering that characteristics such as age, $\mathrm{BMI}$, and the Brinkman index were not significantly different between our patients with overlap syndrome and those with COPD only, these findings suggest that several parameters of overlap syndrome are the same as those of COPD only in the early stage. Therefore, it could be recommended that SDB in the early stage of COPD be treated before the parameters of overlap syndrome worsen compared to those of COPD only. However, since the number of overlap syndrome patients was small $(\mathrm{n}=11)$, further study with a larger cohort would be needed.

\section{Study Limitations}

The present study has a few limitations. First, we could not use the bronchial reversibility test to diagnose COPD. Some patients with other diseases such as bronchial asthma might have been included in the COPD group. Based on information from the patients, 3 of 22 subjects with spirometric obstruction were excluded from the COPD group. Therefore, we made an effort to exclude bronchial asthma patients from the COPD group. Second, we did not perform PSG to verify the portable monitoring device, but this device has been reported to be capable of accurately measuring a wide range of AHI [38], to have a high specificity and sensitivity in comparison with PSG [39], and to provide sufficient quality data to diagnose SDB in unattended home settings [40]. Third, there are no studies comparing polysomnographic data with actigraphic results in COPD. There is a need for more studies to be conducted using actigraphy to confirm if it can really provide new relevant information about sleep disturbance in patients with COPD. However, actigraphy was compared with PSG in patients with sleep disorders such as insomnia and SDB [41]. Also, since we used actigraphy with a sleep diary and portable monitoring, we could obtain more correct data than by using only actigraphy. 


\section{Conclusion}

We showed using actigraphy and type 3 portable monitoring that COPD patients had impaired sleep quality and nocturnal oxygen saturation even with mildto-moderate airflow limitations and few sleep-related symptoms. Sleep disturbances in COPD patients were significantly associated with SDB. By treating SDB in COPD patients more appropriately, nighttime symptoms of COPD, which cannot be detected based on ESS or PSQI scores, would be controlled more effectively. Also, such early intervention for SDB in patients with COPD would induce better sleep quality and a better prognosis. We believe that providing early intervention before the overlap syndrome becomes advanced would be advantageous [7].

\section{Acknowledgements}

This work was supported in part by a grants from the Japanese Ministry of Education, Culture, Sports, Science and Technology, the Respiratory Failure Research Group, and Health Science Research Grants (Comprehensive Research on Lifestyle-Related Diseases Including Cardiovascular Diseases and Diabetes Mellitus) from the Japanese Ministry of Health, Labor and Welfare, the Japan Vascular Disease Research Foundation, research grants from PRESTO JST, the Suzuken Memorial Foundation, the Takeda Science Foundation, the Mitsui Life Social Welfare Foundation, the Chiyoda Kenko Kaihatsu Jigyodan Foundation, and the Health Science Center Foundation.

\section{Financial Disclosure and Conflicts of Interest}

This was not an industry-supported study. The Department of Respiratory Care and Sleep Control Medicine is funded by endowments from Philips-Respironics, Teijin Pharma, and Fukuda Denshi to Kyoto University. The remaining authors indicate no financial conflicts of interest.

\section{References}

1 Murray CJ, Lopez AD: Evidence-based health policy - lessons from the Global Burden of Disease Study. Science 1996;274:740-743.

- 2 Fukuchi Y, Nishimura M, Ichinose M, et al: COPD in Japan: the Nippon COPD Epidemiology study. Respirology 2004;9:458-465.

3 Flenley DC: Sleep in chronic obstructive lung disease. Clin Chest Med 1985;6:651-661.

4 Klink M, Quan SF: Prevalence of reported sleep disturbances in a general adult population and their relationship to obstructive airways diseases. Chest 1987;91:540-546.

5 Collop N: Sleep and sleep disorders in chronic obstructive pulmonary disease. Respiration 2010;80:78-86

-6 Sanders MH, Newman AB, Haggerty CL, et al: Sleep and sleep-disordered breathing in adults with predominantly mild obstructive airway disease. Am J Respir Crit Care Med 2003;167:7-14.

7 Marin JM, Soriano JB, Carrizo SJ, et al: Outcomes in patients with chronic obstructive pulmonary disease and obstructive sleep apnea: the overlap syndrome. Am J Respir Crit Care Med 2010;182:325-331

8 Agusti A, Hedner J, Marin JM, et al: Night time symptoms: a forgotten dimension of COPD. Eur Respir Rev 2011;20:183-194.

-9 Bednarek M, Plywaczewski R, Jonczak L, et al: There is no relationship between chronic obstructive pulmonary disease and obstructive sleep apnea syndrome: a population study. Respiration 2005;72:142-149.

10 McNicholas WT: Chronic obstructive pulmonary disease and obstructive sleep apnea: overlaps in pathophysiology, systemic in- flammation, and cardiovascular disease. Am J Respir Crit Care Med 2009;180:692-700.

-11 Shiina K, Tomiyama H, Takata Y, et al: Overlap syndrome: additive effects of COPD on the cardiovascular damages in patients with OSA. Respir Med 2012;106:1335-1341.

12 Nunes DM, de Bruin VM, Louzada FM, et al: Actigraphic assessment of sleep in chronic obstructive pulmonary disease. Sleep Breath 2012;17:125-132.

13 Ministry of Economy, Trade and Industry of Japan: Industrial activity analysis 2011 (in Japanese). http://www.meti.go.jp/statistics/ toppage/report/bunseki/pdf/h23/h4a1112j1. pdf (accessed May 13, 2014).

14 Nakayama-Ashida Y, Takegami M, Chin K, et al: Sleep-disordered breathing in the usual lifestyle setting as detected with home monitoring in a population of working men in Japan. Sleep 2008;31:419-425.

15 Shinkoda H, Matsumoto K, Hamasaki J, et al: Evaluation of human activities and sleep-wake identification using wrist actigraphy. Psychiatry Clin Neurosci 1998;52: 157-159.

16 Jean-Louis G, von Gizycki H, Zizi F, et al: Determination of sleep and wakefulness with the actigraph data analysis software (ADAS). Sleep 1996;19:739-743.

7 Knutson KL, Van Cauter E, Zee P, et al: Crosssectional associations between measures of sleep and markers of glucose metabolism among subjects with and without diabetes: the Coronary Artery Risk Development in Young Adults (CARDIA) Sleep Study. Diabetes Care 2011;34:1171-1176.
18 Mansoor GA, White WB, McCabe EJ, et al: The relationship of electronically monitored physical activity to blood pressure, heart rate, and the circadian blood pressure profile. Am J Hypertens 2000;13:262-267.

19 Johns MW: A new method for measuring daytime sleepiness: the Epworth Sleepiness Scale. Sleep 1991;14:540-545.

20 Fukuhara S, Takegami M, Suzukamo Y, et al: The Japanese version of Epworth Sleepiness Scale (JESS). J Jap Respir Soc 2006;44:896-898.

21 Buysse DJ, Reynolds CF 3rd, Monk TH, et al: The Pittsburgh Sleep Quality Index: a new instrument for psychiatric practice and research. Psychiatry Res 1989;28:193-213.

22 Doi Y, Minowa M, Uchiyama M, et al: Psychometric assessment of subjective sleep quality using the Japanese version of the Pittsburgh Sleep Quality Index (PSQI-J) in psychiatric disordered and control subjects. Psychiatry Res 2000;97:165-172.

23 Japanese Respiratory Society: Reference values of spirogram and arterial blood gas levels in Japanese. J Jap Respir Soc 2001;39:appendix.

24 Furihata R, Uchiyama M, Takahashi S, et al: The association between sleep problems and perceived health status: a Japanese nationwide general population survey. Sleep Med 2012;13:831-837.

25 Parish JM: Sleep-related problems in common medical conditions. Chest 2009; 135 563-572.

26 Cormick W, Olson LG, Hensley MJ, et al: Nocturnal hypoxaemia and quality of sleep in patients with chronic obstructive lung disease. Thorax 1986;41:846-854. 
27 Argyropoulos SV, Hicks JA, Nash JR, et al: Correlation of subjective and objective sleep measurements at different stages of the treatment of depression. Psychiatry Res 2003;120: 179-190.

28 Swanney MP, Ruppel G, Enright PL, et al: Using the lower limit of normal for the $\mathrm{FEV}_{1} /$ FVC ratio reduces the misclassification of airway obstruction. Thorax 2008;63:1046-1051.

29 Ministry of Internal Affairs and Communications: 2006 Survey on Time Use and Leisure Activities. 2006. http://www.stat.go.jp/english/data/shakai/2006/pdf/jikan-a.pdf (accessed May 13, 2014).

30 NHK Broadcasting Culture Research Institute: Sleeping time keeps decreasing, male housework time is increasing from the 2010 NHK Japanese Time Use Survey. http://www. nhk.or.jp/bunken/english/reports/pdf/report_110401.pdf (accessed May 13, 2014).
31 Celli BR, Halbert RJ, Isonaka S, et al: Population impact of different definitions of airway obstruction. Eur Respir J 2003;22:268-273.

32 Young T, Palta M, Dempsey J, et al: The occurrence of sleep-disordered breathing among middle-aged adults. N Engl J Med 1993;328:1230-1235.

33 Peppard PE, Young T, Barnet JH, et al: Increased prevalence of sleep-disordered breathing in adults. Am J Epidemiol 2013; 177:1006-1014

34 Tufik S, Santos-Silva R, Taddei JA, et al: Obstructive sleep apnea syndrome in the São Paulo Epidemiologic Sleep Study. Sleep Med 2010;11:441-446.

35 Yamagishi K, Ohira T, Nakano H, et al: Crosscultural comparison of the sleep-disordered breathing prevalence among Americans and Japanese. Eur Respir J 2010;36:379-384.

-36 Sleep-related breathing disorders in adults: recommendations for syndrome definition and measurement techniques in clinical research. Sleep 1999;22:667-689.
37 BaHammam A: Comparison of nasal prong pressure and thermistor measurements for detecting respiratory events during sleep. Respiration 2004;71:385-390.

38 Cunnington D, Menagh J, Cherry G: Comparison of full in laboratory polysomnography to a portable sleep data acquisition device. Am J Respir Crit Care Med 2003; 167:A405.

39 Kondo T, Fukushima K, Iga T: Sensitivity and specificity of automated portable device for diagnosing sleep apnea syndrome (Morphase). Respir Circ 2004;52:427-431.

40 Menagh J, Cherry G, Cunnington D: The utility of unattended, at home diagnostic sleep studies using a new portable sleep data acquisition device. Am J Respir Crit Care Med 2003;167:A406

41 Ancoli-Israel S, Cole R, Alessi C, et al: The role of actigraphy in the study of sleep and circadian rhythms. Sleep 2003;26:342-392. 